\author{
Research Article \\ www.ijrap.net (ISSN:2229-3566)
}

\title{
A SYSTEMATIC COMPARATIVE QUALITY ASSESSMENT AND STANDARDIZATION OF DASHAN SANSKAR CHURNA: AN AYURVEDIC FORMULATION
}

Mehul Mehta ${ }^{1 *}$, Sushant Sud ${ }^{2}$, Urvi Dave ${ }^{3}$, Vivek Dixit ${ }^{4}$

${ }^{1}$ HOD, Senior Lecturer, Department of Quality Control, Indian Institute of Ayurvedic Pharmaceutical Sciences, Gujarat Ayurved University, Jamnagar, Gujarat, India

${ }^{2}$ I/c HOD and Reader, Department of Agad Tantra, Shri Gulabkunverba Ayurved Mahavidyalaya, Gujarat Ayurved University, Jamnagar, Gujarat, India

${ }^{3}$ Professor, Department of Roga Nidan Evum Vikriti Vignan, Motherhood Ayurved Medical College, Roorkee, Haridwar, Uttarakhand, India

${ }^{4}$ General Manager, Production, Multani Pharmaceuticals, Roorkee, Haridwar, Uttarakhand, India

Received on: 31/03/20 Accepted on: 21/05/20

\begin{abstract}
*Corresponding author
E-mail: mehul_0016@yahoo.co.in
\end{abstract}

DOI: $10.7897 / 2277-4343.110357$

\begin{abstract}
Dashan Sanskar Churna is one of the widely prescribed churna stated in AFI, used in dental problems which are achieved by the abrasive effect of Khatika, whereas the other ingredients concurrently exhibit their particular therapeutic and effects e.g. destruction of bad breath by aromatic ingredients and decolorizing activity by Supari Bhasma. The objective of the study was to put up analytical parameters, along with development of finger printing of Dashan Sanskar Churna and to compare analytical data with that of market samples available. A detailed comparative study of laboratory sample with two market samples has been done conform the same physicochemical parameters along with HPTLC patternfor Quality review and Standardization. Qualitative tests showed the presence of tannins, alkaloids, saponins, glycosides, triterpenoids and calcium. All three samples showed significantly less variations in physicochemical parameters. Colour and percentage of volatile oil was marginally low in the MS-II reflecting the quality of raw materials used. The total tannin in the laboratory prepared sample is $5.60 \% \mathrm{w} / \mathrm{w}$ whereas the findings in market samples were almost half of it i.e. $3 \% \mathrm{w} / \mathrm{w}$ MS-I and $2.64 \% \mathrm{w} / \mathrm{w}$ MS-II. Quantitative estimation of calcium was significantly less as in laboratory sample it was $45 \% \mathrm{w} / \mathrm{w}$, in MS - I, $41 \% \mathrm{w} / \mathrm{w}$ and in MS - II sample II $43.3 \% \mathrm{w} / \mathrm{w}$. It can be concluded in case of HPTLC of volatile oil of MS-II no characteristic spots were observed, this may be due to the use of sub-standard quality raw drugs.
\end{abstract}

Keywords: Dashan Sanskar Churna, Physico-chemical parameters, HPTLC, Standardization

\section{INTRODUCTION}

Present era is synonymous to "Era of technology and information". Keeping in view today's lifestyle everybody expects a miracle therapy which comes at the cost of affecting the other part of body and thus vicious circle is started, curing one thing and affecting the other. Standardization of Ayurvedic formulations is an important aspect of research in Indian system of medicine and essential for worldwide acceptance and globalization of Ayurveda. So, there is need of method development to ascertain standards for quality and purity of raw drugs as well as formulations to maintain their therapeutic efficacy. ${ }^{1,2}$

Dashan Sanskar Churna is one of the widely prescribed Churna mentioned in Ayurvedic formulary of India and is used in problems related to tooth and gums. In case of Dashan Sanskar Churna contents are Shunthi, Haritaki, Musta, Kattha, Karpur, Supari Bhasm, Marich, Lavang, Twak and Khatika. Here, the formulation's half part is Khatika alone and the rest half contains other nine ingredients. So the main activity of the formulation i.e. dental care is achieved by the abrasive effect of Khatika, whereas the other ingredients simultaneously exhibits their particular therapeutic and allying effects e.g. destruction of bad breath by aromatic ingredients and decolorizing activity by supari bhasma. Hence in the present study a comparative pharmaceuticalanalytical study of Dashan Sanskara prepared classically, and 2 market samples is attempted with current Quality control and assurance methodologies ${ }^{3-5}$.

\section{Aims and Objectives}

- To develop parameters for analysis of 'Dashan Sanskar Churna' to ensure it's in process and finished product quality

- To develop finger printing (HPTLC) of Dashan Sanskar Churna.

- To compare analytical data with that of market samples.

\section{MATERIAL AND METHODS}

The current work is i.e. "A Systematic Comparative Quality Assessment and Standardization of Dashan Sanskar Churna - An Ayurvedic Formulation" was planned in the following stages Viz

- Preparation and procurement of Dashan Sanskar Churna.

- Finished product standardization with comparative study to market sample.

\section{Preparation and Procurement of Dashan Sanskar Churna}

As per the plan of study the next step is to prepare the laboratory sample of Dashan Sanskar Churna by using the authenticated raw material, reduced to powder form and passed through $80 \#$ sieve. And also, procurement of two market samples is done in order to 
fulfill the criteria of comparative study. Two market samples were named MS-I and MS-II. Therefore, the sample prepared in laboratory is used as standard Dashan Sanskar Churna and for comparison two market samples were also procured. The composition of Dashan Sanskar Churna as per "Ayurvedic formulary of India" Part-II has been presented in Table $1^{6}$.

\section{Procedure}

The required quantity of powdered raw drugs is taken in accurate ratio and mixed homogenously. The so obtained formulation is used as standard Dashan Sanskar Churna and labelled as in-house sample.

\section{Finished Product Standardization}

The main aim of the study is to get some guidelines for standardization of Dashan-Sanskar Churna by setting some standards. For this purpose, the in-house sample was analyzed throughly and the obtained results were compared with the analytical results of market samples. So, the results deduced with the in-house sample were considered as standard and the standardization pattern is developed. All the samples were analyzed by implementing variuos pharmacognostic, physicochemical parameters, chromatographic as well as other instrumental techniques?

Table 1: Dashan Sanskar Churna - Ingredients

\begin{tabular}{|c|c|c|c|c|c|}
\hline S. No. & Name of Ingredient & Latin name and Family & Part Used & Quantity Given & Quantity Taken \\
\hline 1. & Shunthi & Zingiber officinale (Zingiberaceae) & Rhizome & 1 Part & $13.88 \mathrm{G}$ \\
\hline 2. & Haritaki & Terminalia chebula (Combretacae) & Fruit Pulp & 1 Part & $13.88 \mathrm{G}$ \\
\hline 3 & Musta & Cyperus rotundus (Cyperaceae) & Rhizome & 1 Part & $13.88 \mathrm{G}$ \\
\hline 4 & Khadir (Kattha) & Uncaria gambir (Rubiaceae) & $\begin{array}{c}\text { Leaves and Shoots Aqueous } \\
\text { Extract }\end{array}$ & 1 Part & $13.88 \mathrm{G}$ \\
\hline 5 & Karpur & Cinnamomum camphora (Lauraceae) & Exudate & 1 Part & $13.88 \mathrm{G}$ \\
\hline 6 & Supari Bhasma & Areca catechu (Palmae) & $\begin{array}{c}\text { Ash obtained from Carbonisation } \\
\text { of Seed. }\end{array}$ & 1 Part & $13.88 \mathrm{G}$ \\
\hline 7 & Marich & Piper nigrum (Piperaceae) & Fruit & 1 Part & $13.88 \mathrm{G}$ \\
\hline 8 & Lavanga & Syzygium aromaticum (Myrtaceae) & Flower Bud & 1 Part & $13.88 \mathrm{G}$ \\
\hline 9 & Twak & Cinnamomum zeylanicum (Lauraceae) & Bark & 1 Part & $13.88 \mathrm{G}$ \\
\hline 10 & Khatika & & & 9 Part & $125 \mathrm{G}$ \\
\hline
\end{tabular}

Table 2: Organoleptic Characters

\begin{tabular}{|c|c|c|c|}
\hline & \multicolumn{3}{|c|}{ Sample } \\
\cline { 2 - 4 } & In House & Ms-I & Ms-Ii \\
\hline Colour & Greyish Brown & Light Brown & Light Brown \\
\hline Odour & Characteristic Aromatic & Characteristic Aromatic & Characteristic Aromatic \\
\hline Taste & Astringent and Pungent & Astringent and Pungent & Astringent and Pungent \\
\hline Texture & Smooth & Smooth & Smooth \\
\hline
\end{tabular}

Table 3: Analytical Values for Physico Chemical Parameters for Dashan Sanskar Churna

\begin{tabular}{|c|c|c|c|}
\hline Parameters & \multicolumn{3}{|c|}{ Sample } \\
\cline { 2 - 4 } & In-House & Ms-I & Ms-Ii \\
\hline Particle Size Getting Through 60\# (\% W/W) & 97.8 & 98.6 & 93.3 \\
\hline Particle Size Passing Through 85\# (\% W/W) & 89.7 & 90.6 & 84.5 \\
\hline Loss On Drying at $105^{\circ} \mathrm{c}(\% \mathrm{~W} / \mathrm{W})$ & 9.52 & 7.1 & 9.57 \\
\hline Ash Value $(\% \mathrm{~W} / \mathrm{W})$ & 51.14 & 53.7 & 55.8 \\
\hline Acid Insoluble Ash $(\% \mathrm{~W} / \mathrm{W})$ & 7.75 & 6.1 & 6.4 \\
\hline Water Soluble Ash $\%$ W/W) & 1.7 & 1.1 & 1.4 \\
\hline Water Soluble Extractive (\% W/W) & 8.84 & 10.80 & 8.83 \\
\hline Alcohol Soluble Extractive (\% W/W) & 12.5 & 12.42 & 8.82 \\
\hline Ph Value & 6.81 & 6.26 & 6.80 \\
\hline Volatile Oil Content (\% V/W) & 1.2 & 1 & 0.4 \\
\hline Colour of Volatile Oil & Transparent & Transparent & Dull Yellow Coloured \\
\hline
\end{tabular}

Table 4: Qualitative Tests of Dashan Sanskar Churna

\begin{tabular}{|c|c|c|c|}
\hline \multirow{2}{*}{ Test } & \multicolumn{3}{|c|}{ Sample } \\
\cline { 2 - 4 } & In House & Ms-I & Ms-Ii \\
\hline For Glycosides & + & + & + \\
\hline For Alkaloids & + & + & + \\
\hline For Tannins & + & + & + \\
\hline For Tri Terpenoids & + & + & + \\
\hline For Saponins & + & + & + \\
\hline
\end{tabular}

Table 5: Calcium Content of Dashan Sanskar Churna

\begin{tabular}{|c|c|}
\hline Sample & Calcium Content \% W/W \\
\hline In House & 45 \\
\hline Ms-I & 41 \\
\hline Ms-Ii & 43.4 \\
\hline
\end{tabular}


Table 6: Total Tannin Content

\begin{tabular}{|c|c|}
\hline Sample & Total Tannin Content (\% W/W) \\
\hline In House & 5.60 \\
\hline Ms-I & 3 \\
\hline Ms-Ii & 2.64 \\
\hline
\end{tabular}

Table 7: HPTLC-Under Short UV (254 Nm)

\begin{tabular}{|c|c|c|}
\hline S. No. & Name of Sample & Rf. \\
\hline 1 & Kattha & $0.26,0.38,0.45,0.62,0.69,0.73$ \\
\hline 2 & Catechin & 0.45 \\
\hline 3 & Haritaki & $0.06,0.12,0.17,0.22,0.42,0.45,0.52,0.59,0.65,0.73,0.81$ \\
\hline 4 & Ellagic Acid & 0.46 \\
\hline 5 & Gallic Acid & 0.53 \\
\hline 6 & In House & $0.12,0.42,0.47,0.53,0.63,0.67,0.77,0.90$ \\
\hline 7 & Ms-I & $0.12,0.42,0.47,0.53,0.63,0.67,0.77,0.99$ \\
\hline 8 & Ms-Ii & $0.12,0.42,0.47,0.53,0.63,0.67,0.77,0.90$ \\
\hline 9 & Marich & $0.72,0.80,0.9$ \\
\hline 10 & Piperine & 0.80 \\
\hline
\end{tabular}

(Chromatogram of Methanolic Extract of Samples Developed By Using Mobile Phase - Toluene: Ethylacetate: Formic Acid: Methanol)

Table 8: HPTLC Observation under Short UV (254 Nm)

\begin{tabular}{|c|c|c|}
\hline S. No. & Name of Sample & Rf. \\
\hline 1 & Kattha & $0.16,0.45,0.68$ \\
\hline 2 & Catechin & 0.45 \\
\hline 3 & Haritaki & $0.05,0.51,0.61,0.76,0.41$, \\
\hline 4 & Ellagic Acid & 0.41 \\
\hline 5 & Gallic Acid & 0.51 \\
\hline 6 & In House & $0.41,0.45,0.51,0.72,0.85$ \\
\hline 7 & Ms-I & $0.41,0.45,0.51,0.72,0.85$ \\
\hline 8 & Ms-Ii & $0.40,0.45,0.51,0.72,0.85$ \\
\hline
\end{tabular}

(Chromatogram Developed To Check out the Presence of Tannin Constituents in the Formulation)

Table 9: HPTLC-Observation under Short UV (254 Nm)

\begin{tabular}{|c|c|c|}
\hline S. No. & Name of Sample & Rf. \\
\hline 1 & In House Sample & 0.79 \\
\hline 2 & Ms-I & 0.79 \\
\hline 3 & Ms-Ii & 0.79 \\
\hline 4 & Piperine & 0.79 (Piperine) \\
\hline 5 & Marich & $0.79,0.83$ \\
\hline
\end{tabular}

(To Detect the Presence of Marich in the Formulation)

Table 10: after Derivatizing with Dragendroff's Reagent

\begin{tabular}{|c|c|c|}
\hline S. No. & Name of Sample & Rf. \\
\hline 1 & In House Sample & $0.79,0.90$ \\
\hline 2 & Ms-I & $0.78,0.89,0.19$ \\
\hline 3 & Ms-Ii & $0.79,0.88$ \\
\hline 4 & Piperine & 0.79 \\
\hline 5 & Marich & $0.72,0.79$ \\
\hline
\end{tabular}

Table 11: HPTLC-Observation under Short UV (254 Nm)

\begin{tabular}{|c|c|c|}
\hline S. No. & Name of Sample & Rf. \\
\hline 1 & Lavanga & $0.10,0.62,0.67,0.98$ \\
\hline 2 & Eugenol & - \\
\hline 3 & Shunthi & $0.35,0.38,0.98$ \\
\hline 4 & Shagoal & 0.35 \\
\hline 5 & In House Sample & $0.09,0.16,0.20,0.46,0.61$ \\
\hline 6 & Ms-I & $0.10,0.15,0.19,0.6$ \\
\hline 7 & Ms-Ii & $0.09,0.15,0.20$ \\
\hline 8 & Twak & - \\
\hline 9 & Musta & $0.17,0.30,0.40,0.51$ \\
\hline
\end{tabular}

(Chromatogram of methanolicextract of Samples along with Detection of Individual Ingredients) 
Mehul Mehta et al / Int. J. Res. Ayurveda Pharm. 11 (3), 2020

Table 12: HPTLC-Observations under Long UV (366 Nm)

\begin{tabular}{|c|c|c|}
\hline S. No. & Name of Sample & Rf. \\
\hline 1 & Lavanga & $0.08,0.20,0.29,0.37$ \\
\hline 2 & Eugenol & - \\
\hline 3 & Shunthi & $0.8,0.29,0.34,0.39$ \\
\hline 4 & Shagoal & - \\
\hline 5 & In House Sample & $0.08,0.14,0.18,0.24,0.30,0.48$ \\
\hline 6 & Ms-I & $0.08,0.14,0.18,0.24,0.48$ \\
\hline 7 & Ms-Ii & $0.08,0.14,0.20,0.18,0.24,0.30,0.34,0.48$ \\
\hline 8 & Twak & $0.23,0.36,0.49$ \\
\hline 9 & Musta & $0.31,0.07,0.38$ \\
\hline
\end{tabular}

Table 13: Observations after derivatizing with Anisaldehydesulphuricacid reagent

\begin{tabular}{|c|c|c|}
\hline S. No. & Name of Sample & Rf. \\
\hline 1 & Lavanga & $0.11,0.16,0.25,0.35,0.55,0.91$, \\
\hline 2 & Eugenol & 0.53 \\
\hline 3 & Shunthi & $0.09,0.23,0.35,0.38,0.9$ \\
\hline 4 & Shagoal & 0.35 \\
\hline 5 & In House Sample & $0.08,0.14,0.18,0.24,0.29,0.35,0.53,0.6,0.9,0.91$ \\
\hline 6 & Ms-I & $0.09,0.14,0.24,0.29,0.35,0.53,0.88,0.92$ \\
\hline 7 & Ms-Ii & $0.08,0.13, .0 .23,0.28,0.35,0.53,0.88,0.93$ \\
\hline 8 & Twak & $0.11,0.23,0.92$ \\
\hline 9 & Musta & $0.12,0.17,0.23,0.29,0.36,0.47,0.56,0.89$ \\
\hline
\end{tabular}

Table 14: HPTLC-under Short UV (254 Nm)

\begin{tabular}{|c|c|c|}
\hline S. No. & Name of Sample & Rf. \\
\hline 1 & Lavanga & $0.53,0.77,0.87$ \\
\hline 2 & Eugenol & 0.53 \\
\hline 3 & Shunthi & $0.37,0.47,0.51,0.54,0.69,0.97$ \\
\hline 4 & Shagoal & 0.37 \\
\hline 5 & In House & $0.42,0.52,0.60,0.72,0.99$ \\
\hline 6 & Ms-I & $0.42,0.52,0.60,0.96$ \\
\hline 7 & Ms-Ii & - \\
\hline 8 & Twak & 0.56 \\
\hline 9 & Marich & $0.17,0.31,0.36,0.67,0.86,0.99$ \\
\hline 10 & Musta & $0.36,0.42,0.51,0.63,0.69,0.97$ \\
\hline
\end{tabular}

(Chromatogram of Volatile oils of the formulation along with simultaneous detection of individual drug volatile oil in the sample)

Table 15: After Derivatized with AnisaldehydeSulphuric Acid

\begin{tabular}{|c|c|c|}
\hline S. No. & Name of Sample & Rf. \\
\hline 1 & Lavanga & $0.16,0.36,0.53,0.88$ \\
\hline 2 & Eugenol & 0.53 \\
\hline 3 & Shunthi & $0.04,0.15,0.23,0.27,0.37,0.43,0.49,0.57,0.69,0.94$ \\
\hline 4 & Shagoal & 0.38 \\
\hline 5 & In House & $0.30,0.35,0.39,0.48,0.53,0.66,0.94$ \\
\hline 6 & Ms-I & $0.24,0.27,0.32,0.38,0.39,0.42,0.48,0.52,0.69,0.77,0.94$ \\
\hline 7 & Ms-Ii & - \\
\hline 8 & Twak & - \\
\hline 9 & Marich & $0.29,0.38,0.57,0.96$ \\
\hline 10 & Musta & $0.18,0.27,0.33,0.39,0.51,0.58,0.62,0.67,0.71,0.86,0.96$ \\
\hline
\end{tabular}

Table 16: HPTLC-under Short UV (254 Nm)

\begin{tabular}{|c|c|c|}
\hline S. No. & Name of Sample & Rf. \\
\hline 1 & Camphor & 0.70 \\
\hline 2 & In House & $0.07,0.20,0.28,0.36,0.63,0.71,0.84,0.96$ \\
\hline 3 & Ms-I & $0.07,0.21,0.27,0.32,0.70,0.95$ \\
\hline 4 & Ms-Ii & $0.07,0.22,0.30,0.35,0.95$ \\
\hline
\end{tabular}

(Chromatogram of Methanolic Extracts of Sample, Along with the Simultaneous Detection of Camphor in the Formulation) 
Fig. 1 (Plate - 1)

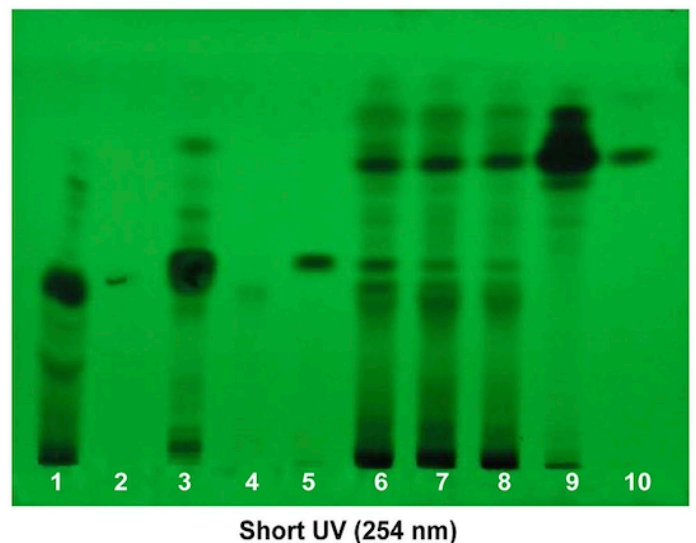

Short UV (254 nm)

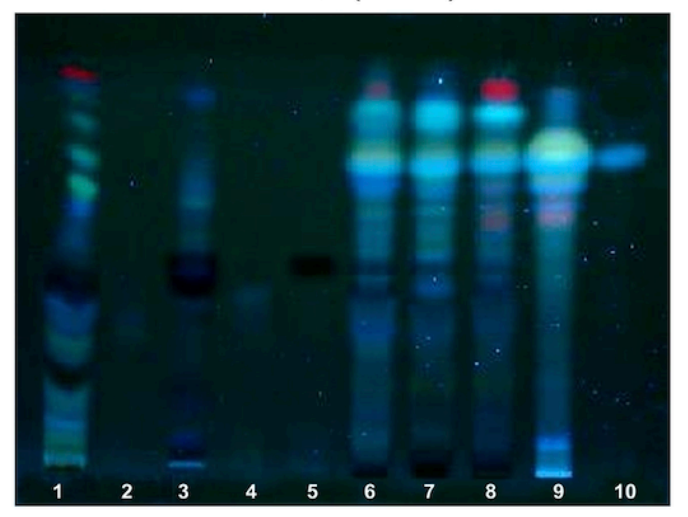

Long UV (366 nm)

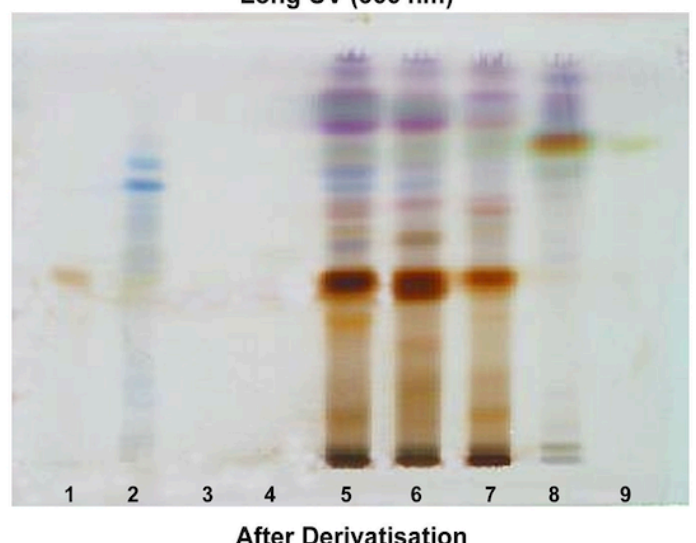

(Anisaldehyde Sulphuric Acid)

Figure 1 (Plate - 1): The chromatogram of methanolic extract of samples developed by using mobile phase Toluene: Ethylacetate: Formic acid: Methanol (6:6:1.8:0.35)
Fig. 2 (Plate - 2)
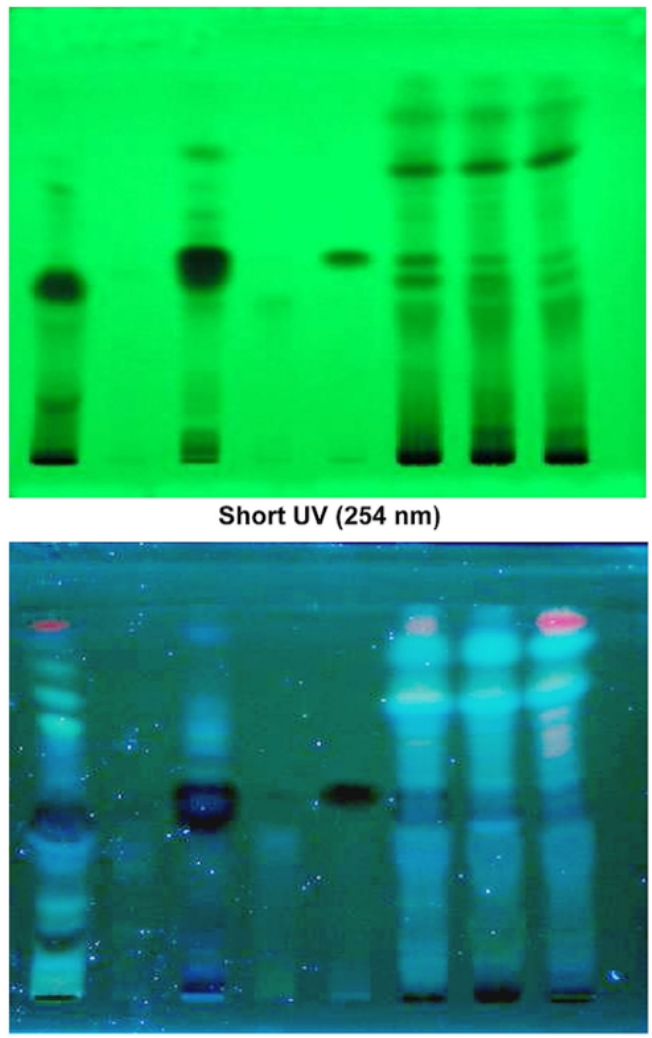

Long UV (366 nm)

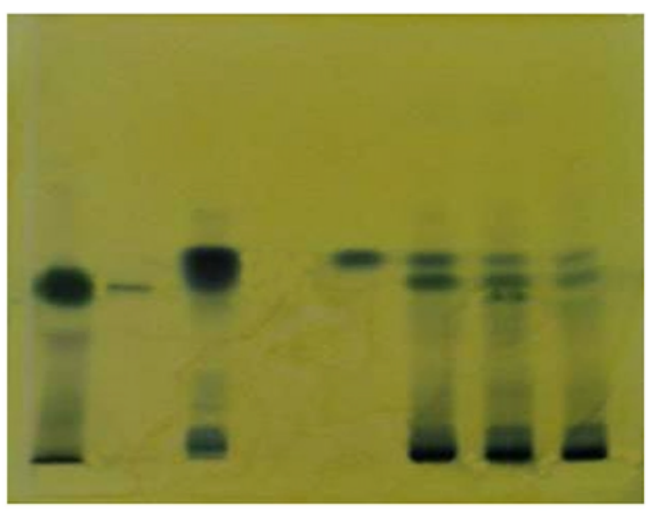

After derivatisation

( $5 \%$ methanolic ferric chloride)

Figure 2 (Plate - 2): The chromatogram developed to check out the presence of tannin constituents in the formulation, along with individual tannin containing ingredients and by using different reference standards 
Mehul Mehta et al / Int. J. Res. Ayurveda Pharm. 11 (3), 2020

Fig. 3 (Plate - 3)

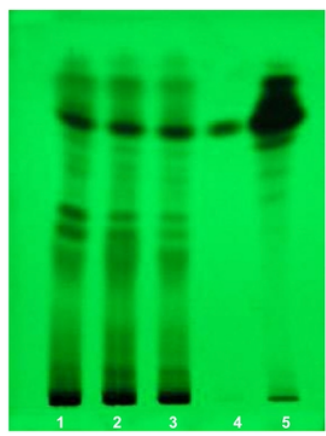

Short UV $(254 \mathrm{~nm})$
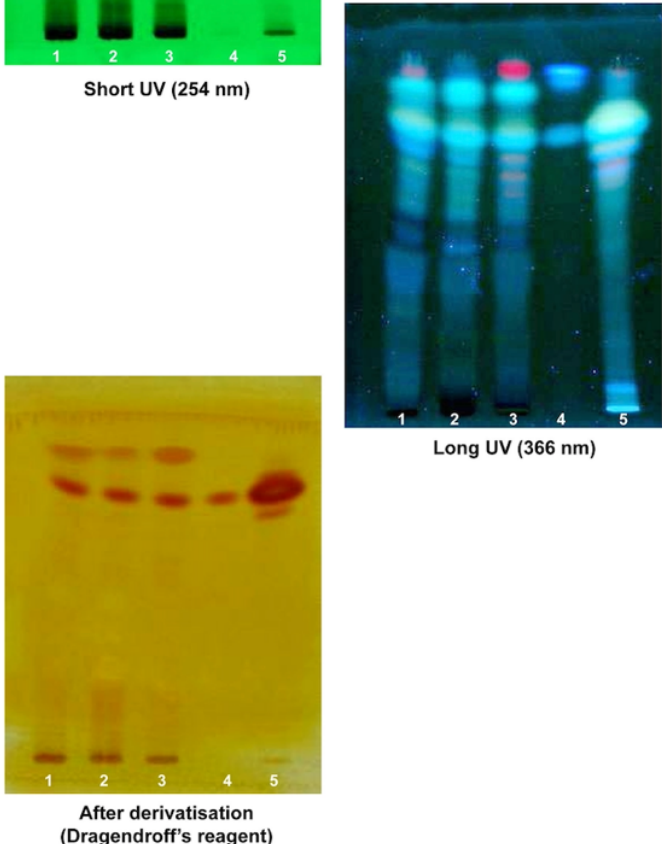

Figure 3 (Plate - 3): This plate is specially designed to detect the presence of Marich in the formulation.

Fig. 5 (Plate - 5)

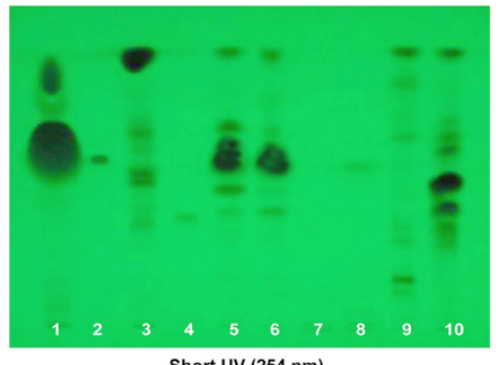

Short UV $(254 \mathrm{~nm})$

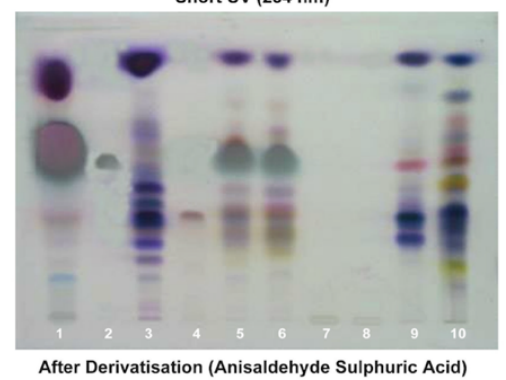

Figure 5: The chromatogram of methanolic extracts of sample, along with the simultaneous detection of camphor in the formulation.
Fig.4 (Plate - 4)
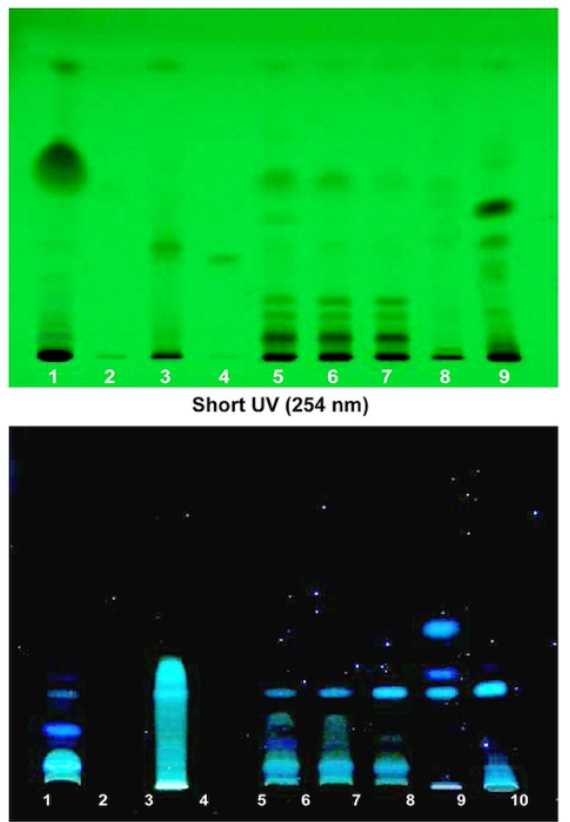

Long UV (366 nm)

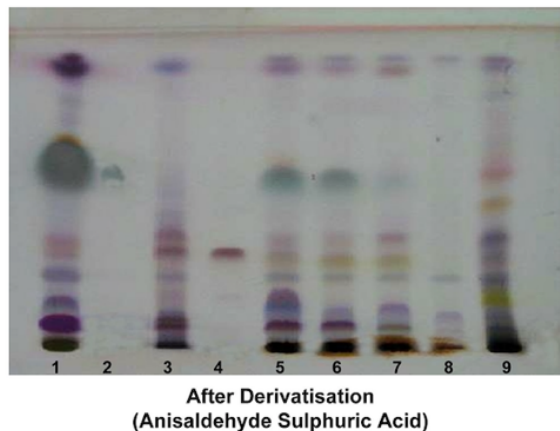

(Anisaldehyde Sulphuric Acid)

Figure 4 (Plate - 4): The chromatogram of Methanolic extract of samples along with detection of individual ingredients (i.e. lavang, shunthi, twak and musta) in the formulation
Fig. 6 (Plate - 6)

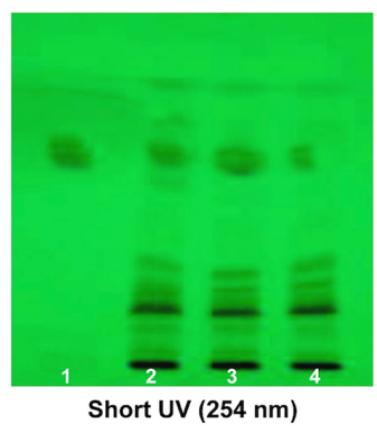

Figure 6: Methanolic extracts of samples showed a spot at Rf. 0.70 that matches with the spot of camphor in Track - 1 . 


\section{RESULTS AND DISCUSSION}

As already described under materials and methods, for standardization purpose in house (laboratory) sample of Dashan Sanskar Churna was prepared and procured and used as a standard sample and two market samples viz. MS-I and MS-II were procured from market for comparison purpose. All the samples were analyzed by using various parameters such as naked eye, pharmacognostical, physico-chemical and other instrumental methods. The data evolved from all the standardization parameters are revealed and discussed under this section.

\section{A. Organoleptic Character}

The organoleptic characters of the laboratory sample and market samples were analyzed and presented in Table 2.

The basic difference lies in the colour of sample, as in laboratory sample Supari, bhasma has been added in equal quantity to other ingredients while on commercial scale, first Supari is taken equal to other ingredients and then it is reduced to Bhasma. This may be the reason behind variation in color between standard and market samples. Astringent taste and odour is perceived because 6 ingredients of the formulation are aromatic in nature, camphor (Cinnamomum camphora) is mainly responsible for aromatic taste and odour. The half part of the formulation is Khatika (50\%) and when reduced to powder form it becomes even smoother, but a little grittiness is felt after touching the formulation. ${ }^{8,9}$

\section{B. Micro-Chemical Tests}

1. When samples of Churna were treated with iodine solution presence of blue colour indicated the presence of starch.

2. Volatile oil of the formulation when treated with $10 \%$ aqueous phenyl hydrazine hydrochloride solution, rod shaped crystals were observed.

3. Samples when treated with $5 \%$ alcoholic ferric chloride solution, blue colour was observed indicating the presence of Tannins.

4. Powder of Churna when treated with dilute hydrochloric acid soluble crystals of calcium oxalate were found.

5. Powder of Churna when treated with phloroglucinol and HCL (1:1) gave pink colour indicating the presence of vascular bundles / lignified sclerenchyma. / Pericyclicfibres / stone cells.

6. Solution of formulation when treated with ammonium oxalate solution, yield a white, precipitate which is soluble in hydrochloric acid and insoluble in acetic acid.

Test number 2 when applied to volatile oil of MS-II desired characteristics were not observed indicating the inferior quality of raw material used. ${ }^{8,9}$

\section{Physico-Chemical Parameters}

Comparative physico-chemical values of in-house, MS-I and MSII samples of Dashan Sanskar Churna are shown in Table 3.

Analysis of the data presented in above table reveals that in the laboratory sample and the two market samples more than $95 \%$ of the sample pass through 60 mesh and $85 \%$ pass through 85 mesh. Except MS-II both the samples pass about 90\% through 85 meshes. Loss on drying of all the samples ranges from $7-9 \%$ which reflects about the controlled level of moisture in the sample. Total ash shows a significant values and ranges from $51-$ $55 \%$ as half part of the formulation is khatika. And due to some reason acid insoluble ash is also found to be $6-7 \%$ which tells about the silicacious matter. However, water soluble ash is considerably less almost about $1 \%$.

Water soluble extractive is almost similar, except in MS-I which shows an increase in this value as compared to the other 2 samples. This may be due to quality of raw material used. Alcohol soluble extractive of all the sample ranges from $8-12 \% \mathrm{w} / \mathrm{w}$. Volatile oil content of in house and MS-I shows similar results while in MS-II volatile oil content was found to be very less i.e. $0.4 \% \mathrm{v} / \mathrm{w}$. In the formulation lavang and twak are the dominant source of volatile oil as compared to other aromatic ingredients. The low volatile oil content in MS-II may be due to either poor quality of lavang and twak or addition of less than required amount of both the ingrtedients in the formulation. Except MS-II colour of the volatile oil is transparent. It reveals the inferior quality of raw materials used..$^{8-10}$

\section{Qualitative Tests}

All the 3 samples viz. in house and the 2 market samples were tested qualitatively for the presence of different phytoconstituents in the formulation. The obtained results of the qualitative tests are mentioned in Table 4.

\section{E. Quantitative Estimation}

\section{Determination of calcium content}

The half part of formulation contains khatikachurna and khatika is nothing but chalk containing chiefly calcium carbonate (The AFI). So, the Calcium content of all the samples was determined quantitatively. The data evolved from estimation is presented in Table 5. The half part of formulation contains Khatika so calcium content was determined. In all the three samples total calcium content was ranging from $41-45 \% \mathrm{w} / \mathrm{w} .{ }^{9,10}$

\section{Total tannin content}

Total tannin content of all the samples was determined and tabulated in Table 6. Tannin is the main phytoconstituent in the formulations. The main source of tannin in the formulation is Kattha i.e. pale catechu and the other one is haritaki (T. chebula). In both the market samples the value of tannin is found to be considerably less as compared to in house sample. It clearly reflects the inferior quality of ingredients used in market samples. ${ }^{9,10}$

\section{F. High Performance Thin Layer Chromatographic Study}

A variety of chromatograms were developed under different conditions using HPTLC technique Chromatograms are present in various figures. ${ }^{11,12}$

Figure 1 (Plate - 1) Represents the chromatogram of methanolic extract of samples developed by using mobile phase Toluene: Ethylacetate: Formic acid: Methanol (6:6:1.8:0.35), details of chromatogram are as follows:

Track $-1:$ Pale catechu (Kattha)

Track $-2:$ Catechin (reference standard)

Track $-3:$ Haritaki

Track -4 : Ellagic acid (reference standard)

Track -5 : Gallic acid (reference standard)

Track -6 : In house sample

Track -7 : MS-I

Track $-8:$ MS-II

Track - 9: Marich

Track - 10: Piperine (reference standard) 
The chromatogram obtained after viewing the plate at $254 \mathrm{~nm}$ has been presented in Figure. The details of the chromatograms under different conditions were recorded and tabulated in Table 7.

From the above explained chromatogram the presence of Kattha, Haritaki and Marich in the formulation can be easily detected. In track -1 the zone at Rf. 0.45 is matching with standard catechin, in track 3 zone at Rf. 0.45 and 0.52 are matching with standards ellaic and gallic acid respectively. In track 9 Zone at Rf. 0.80 is matching with standard piperene. Combinely all these zones at nearly same Rf. can be seen in tracks 6,7 and 8 i.e. of formulations. Under long U.V. (366 nm) also the same data was observed except in track 8 a red spot at Rf. 0.92 was seen additionally. The same data was recorded, after the plate was derivatized with anisaldehydesulphuric acid reagent.

Figure 2 (Plate - 2) shows the chromatogram developed to check out the presence of tannin constituents in the formulation, along with individual tannin containing ingredients and by using different reference standards. Details of the chromatogram are as follows Table 8 .

Track $-1:$ Kattha

Track $-2:$ Catechin (reference standard)

Track $-3:$ Haritaki

Track -4 : Ellagic acid (reference standard)

Track - 5: Gallic acid (reference standard)

Track - 6: In house sample

Track - 7 : MS-I

Track $-8:$ MS-II

Mobile phase - Toluene: Ethylacetate: Formic acid: Methanol (6:6:1.8:0.35).

After thoroughly going through above told Rf. values presence of Kattha and Haritaki can be easily detected in the formulation. In tracks 6, 7, and $8 \mathrm{Rf}$ at $0.41,0.45$ and 0.51 indicates the presence of individual compound by the help of reference standards used. The same results were obtained after observing the plate under long U.V. (366 nm) and after derivatizing the plate with $5 \%$ methanolic ferric chloride solution.

Figure 3 (Plate - 3): This plate is specially designed to detect the presence of Marich in the formulation.

Reference standard piperine was used. Results obtained after observing the plate under $254 \mathrm{~nm}$ and recorded are presented here in Table 9.

Track $-1:$ In house sample

Track - 2: MS-I

Track $-3:$ MS-II

Track -4 : Piperine (reference standard)

Track -5 : Marich

Mobile phase: Toluene: Ethylacetate: Formic acid: Methanol (6:6:1.8: 0.35).

From the Figure and Rf obtained detection of marich in all in all the samples in clearly indicated. Rf 0.79 in track 4 (piperine) is found to be matching in all the tracks. Same results were observed after examining the plate under long U. V. (366 nm). After derivatizing the plate with dragendroff's reagent some additional spots were observed and recorded which are presented and tabulated in Table 10.

Dragendorff's reagent is used to identify mainly alkaloidal constituents. So, after spraying the plate after Dragendorff's reagent various spots (orange coloured) representing alkaloids including piperine can be easily observed.

Figure 4 (Plate - 4) Shows the chromatogram of Methanolic extract of samples along with detection of individual ingredients (i.e. lavang, shunthi, twak and musta) in the formulation. Rf Under different visualization conditions were recorded and tabulated here in Table 11.

\author{
Track -1 : Lavang \\ Track - 2: Eugenol (reference standard) \\ Track -3 : Shunthi (hexane extract) \\ Track -4 : Shagoal (reference standard) \\ Track $-5:$ In house sample \\ Track -6 : MS-I \\ Track $-7:$ MS-II \\ Track - 8: Twak (chloroform: hexane (1:1) extract) \\ Track -9 : Musta
}

Mobile phase - Toluene: Ethyl acetate (9.3: 0.7)

Observations after derivatizing the plate with anisaldehyde sulphuric acid reagent are mentioned in the Table 12 and 13.

Under long and short U.V. no significant result was observed, but after derivatizing the plate with anisaldehydesulphuric acid reagent significant and comparative results were obtained.

In track 5, 6, $7 \mathrm{Rf}$ at 0.53 , mainly confirms the presence of lavanga in the samples, $\mathrm{Rf}$ at 0.35 and 0.24 confirms the presence of Shunthi in the sample. The detection was made even more easily because by using reference standards eugenol and shagoal. Standard Rf. of compounds was obtained which further worked as indicator. No matching $\mathrm{Rf}$ of twak in the sample was found. Rf. $0.12,0.17,0.29,0.36$ in tracks $5,6,7$ represents and confirms the presence of musta in the samples.

Figure 5 (Plate - 5) shows the chromatogram of Volatile oils of the formulation along with simultaneous detection of individual drug volatile oil in the sample. Details of the chromatogram are:

Track -1 : Volatile oil of lavanga

Track - 2: Eugenol (Reference Standard)

Track -3 : Volatile oil of Shunthi

Track -4 : Shagoal

Track - 5: Volatile oil of in-house sample

Track - 6: Volatile oil of MS-I

Track -7 : Volatile oil of MS-II

Track -8 : Volatile oil of Twak

Track - 9: Volatile oil of Marich

Track - 10: Volatile oil of Musta

Mobile phase: Toluene: Ethyl acetate (9.3: 0.7),

Rf Obtained after observing the plate under short U.V. (254 nm) are shows in Table 14; after the plate was derivatized with anisaldehydesulphuric acid reagent. The spots were clearer, and comparison was very easy. Rf were recorded and present here in Table 15.

Almost The presence of all volatile oil is detected in the formulation in track 5 And 6 spots at $\operatorname{Rf} 0.39$ and 0.53 represents and confirms the presence of Shunthi and Lavanga respectively in the formulation by the help of reference standards used. $\mathrm{Rf}$ at 0.60 may be due to the presence of twak, 0.37 and 0.67 matches with the Rf obtained from chromatogram of marich. While Rf. 0.51 and 0.60 are found to be similar with Rf. obtained in chromatogram of Musta. In track 7 (MS-II) no spots were visible 
either under short U.V. (254 nm) or after spraying the plate with anisaldehydesulphuric acid reagent this clearly reflects about the quality of ingredients used, either the quality is inferior, or the ingredients are added in a less proportion. In track 8 (Twak) also only one spot is visible under short U.V. (254 nm) with Rf 0.56 this also shows that the twak used in making the in-house sample was of sub-standard quality.

Figure 5 shows the chromatogram of methanolic extracts of sample, along with the simultaneous detection of camphor in the formulation. Details of the chromatograms are

Track $-1:$ Camphor

Track - $2:$ In - house sample

Track -3 : MS-I

Track -4 : MS-II

Mobile phase: Chloroform

Rf Recorded under short U.V. (254 nm) are given in Table 16.

From Figure 6 it can be observed that methanolic extracts of samples showed a spot at Rf. 0.70 that matches with the spot of camphor in Track - 1. This spot is however found to be almost absent in MS-II. (Very Faded Spot)

\section{CONCLUSION}

The current study is aimed to construct and set some standards The market samples show colour variation which may be due to adding less amount of supari bhasma as compared to that mentioned in the classical formula. On qualitative tests the samples showed the presence of tannins, alkaloids, saponins, glycosides, triterpenoids and calcium. There was not much variation in the values of majority of physicochemical parameters of the laboratory as well as the market samples. Ash values of all the samples were found to be comparatively high. Colour and percentage of volatile oil was marginally low in the market sample II reflecting the quality of raw materials used.

Quantitative estimation of tannin was carried and the study revealed that total tannin in the laboratory prepared sample is $5.60 \% \mathrm{w} / \mathrm{w}$ where as the findings in market samples were almost half of it i.e. $3 \% \mathrm{w} / \mathrm{w}$ (MS-I) and $2.64 \% \mathrm{w} / \mathrm{w}$ (MS-II) This shows the comparative poor quality of haritaki and kattha used in market samples respectively. Whereas the Khatika being an important ingredient occupying half part $(50 \%)$ of the formulation so, quantitative estimation of calcium was almost comparative, in laboratory sample as $45 \% \mathrm{w} / \mathrm{w}$, in MS - I, $41 \% \mathrm{w} / \mathrm{w}$ and in MS II sample II $43.3 \% \mathrm{w} / \mathrm{w}$. An attempt to establish suitable HPTLC finger printing for Dashan Sanskar Churna has been made in order to identify the presence of different ingredients in it through HPTLC chromatograms and it is concluded in case of HPTLC fingerprinting of volatile oil of MS II no characteristic spots were observed, this may be due to the use of sub standard quality raw drugs. This finding is also supported by the microscopic examination and poor volatile oil yield of the same sample i.e. MS-II. Thus, by implementing organoleptic, pharmacognostic, physicochemical, chromatographic studies it is possible to identity the various ingredients in the formulation. The data evolved from the present study will be very useful for routine quality control and assessment of Dashan Sanskar Churna and also to control the batch to batch variations.

\section{ACKNOWLEDGEMENT}

I would like to thank the PERD centre ahemdabad for providing me the facility of HPTLC for this work. I am grateful to our Librarian, GAU and Jamnagar, India for providing me with the books I needed for the study. I thank my seniors and juniors for their Co-operation during my research work. I would like to convey my special thanks all faculty members for their co operation and skillful assistance in carrying out the analytical procedure.

\section{REFERENCES}

1. Taylor, V.E., Berady, L.R., Pharmacognosy $8^{\text {th }}$ edition, K. M. Varghese Company, Mumbai; 1981. p. 1-25.

2. Pulok M. Quality control of herbal drugs, March 2006, Available from www.info@motherherbs.com/Quality control of herbals/2006. Retrived on March 2006.

3. Newwall, C.A., Anderson, L.A. and Phillipson, J.D., Herbal Medicine, A Guide for health care Professional, $2^{\text {nd }}$ edition, Pharmaceutical Press, London, U.K.; 2002.

4. Polumin M. and Robbins C. The natural pharmacy- An encyclopedic illustrated guide tomedicines from nature, $2^{\text {nd }}$ edition, Dorling Kindersley publisher ltd.; 1992.

5. Kumar V.P. and Shashidhara S., Phytotherpy safety issues, The Eastern Pharma publishers, Nashik; 2001. p. 35-37.

6. Anonymous. The Ayurvedic Formulary of India, Part-II, 1st Edi., Government of India, Ministry of Health and Family Welfare, Dept. of I.S.M. and H., New Delhi; 2002.

7. Anonymous. The Ayurvedic Pharmacopoeia of India, Part-I, Volume-I, 1st Edition, Government of India, Ministry of Health and Family Welfare, Department of Health; 1989.

8. Kasture A.V., Wadokar S.G., Mahadik K.R., More H.N. A Text Book of Pharmaceutical Analysis, Vol.-2, Nirali Prakashan; 2004. p. 234-248.

9. Vogel A.I. A Text Book of Quantitative Inorganic Analysis, ELBS Edition, A Longman Scientific and Technical, Burnt Mill, Harlow, England; 1978. p. 354.

10. Kasture A.V., Wadokar S.G., Mahadik K.R., More H.N. A Text Book of Pharmaceutical Analysis, Vol.-2, Nirali Prakashan; 2004. p. 58-75.

11. Chatwal G.R., Anand S.K. Instrumental Methods of Chemical Analysis, 5th Revised and Enlarged Edition, Himalaya Publishing House Pvt. Ltd, Mumbai; 2002. p. 2.272-2.503, 2.599-2.616; 2.673-2.700.,

12. Jaenchen DE. Planer Chromatography (Instrumental Thinlayer Chromatography), Chapter-5, CAMAG, Muttenz, Switzerland; 1989. p. 129.

\section{Cite this article as:}

Mehul Mehta et al. A Systematic comparative quality assessment and standardization of Dashan Sanskar Churna: An Ayurvedic Formulation. Int. J. Res. Ayurveda Pharm. 2020;11(3):37-45 http://dx.doi.org/10.7897/2277-4343.110357

Disclaimer: IJRAP is solely owned by Moksha Publishing House - A non-profit publishing house, dedicated to publishing quality research, while every effort has been taken to verify the accuracy of the content published in our Journal. IJRAP cannot accept any responsibility or liability for the site content and articles published. The views expressed in articles by our contributing authors are not necessarily those of IJRAP editor or editorial board members. 